Journal Club

Editor's Note: These short reviews of recent JNeurosci articles, written exclusively by students or postdoctoral fellows, summarize the important findings of the paper and provide additional insight and commentary. If the authors of the highlighted article have written a response to the Journal Club, the response can be found by viewing the Journal Club at www.jneurosci.org. For more information on the format, review process, and purpose of Journal Club articles, please see http://www.jneurosci.org/content/ jneurosci-journal-club.

\title{
Molecular Underpinnings of Estradiol-Mediated Sexual Dimorphism of Synaptic Plasticity in the Hippocampus of Rodents
}

\author{
Edgar Bäumler, Lauren Strickland, and Lucia Privitera \\ Richard Morris Laboratory, Centre for Discovery Brain Sciences, University of Edinburgh, Edinburgh EH8 9XD, UK \\ Review of Wang et al.
}

On a population level, males and females excel at different kinds of memory tasks. In particular, men overall have a greater ability to remember spatial representations, whereas women perform better on tasks requiring semantic memory (Andreano and Cahill, 2009). Initial encoding of different types of memories depends on synaptic plasticity in the hippocampus, and previous work has highlighted sexual dimorphism in these mechanisms. Differences have been found, for example, in the induction of long-term potentiation (LTP) at the Schaffer collateral (SC) synapses, which constitute the main excitatory input from CA3 to CA1 of the hippocampus (Vierk et al., 2012).

The sex hormone estradiol (E2) is likely to participate in the molecular underpinnings of sex differences in memory formation, given its local synthesis and widespread effects in the brain (Woolley, 2007). In fact, the inhibition of local E2 production leads to the loss of hippocampal LTP in female, but not in male, rodents (Vierk et al., 2012; Bender et al., 2017). Nonetheless, when exogenous E2 is applied to hippocampal synapses, LTP is

\footnotetext{
Received Nov. 12, 2018; revised Jan. 13, 2019; accepted Jan. 21, 2019. We declare no competing financial interests.

Correspondence should be addressed to Edgar Bäumler at S1546786@ed.ac.uk

https://doi.org/10.1523/JNEUROSCI.2894-18.2019

Copyright $\odot 2019$ the authors $\quad 0270-6474 / 19 / 392160-03 \$ 15.00 / 0$
}

enhanced in both sexes (Kramár et al., 2009). This, in conjunction with the presence of higher levels of hippocampal E2 in males (Ooishi et al., 2012), points toward potential differences in how E2 affects synaptic plasticity in males and females. These might include disparities in the principal estrogen receptor (ER) subtypes involved and alterations in the signaling molecules downstream of these receptors that interact with the LTP pathway.

To investigate these possibilities, Wang et al. (2018) first sought to identify the receptor subtypes that mediate E2 effects on SC-LTP. Application of ER $\alpha$-selective antagonist during theta burst stimulation (TBS) in acute brain slices permitted initial potentiation but impaired stabilization of SC-LTP in female, but not in male

The normal initiation of SC-LTP in females and the immediate effects of antagonist application on LTP stabilization suggest that the effects rely on local synaptic changes as opposed to ER-driven changes in gene expression at the nucleus. To confirm this, Wang et al. (2018) used hippocampal slices taken from NOER (nuclear-only ER1) and MOER (membraneonly $\mathrm{ER} \alpha$ ) mutant mice, which lack membrane-associated or nuclear $\mathrm{ER} \alpha$, respectively (Pedram et al., 2013, 2014). As predicted, in slices taken from female NOER mice, LTP failed to stabilize, whereas LTP was unaffected in female
MOER mice. In male mice, LTP was not altered by either mutation. Although these results do not exclude contributions of nuclear $\mathrm{ER} \alpha$ to longer-term LTP maintenance, they strongly suggest that membrane-associated $\mathrm{ER} \alpha$ is necessary for normal SC-LTP stabilization in females. Collectively, these observations provide compelling evidence that the sexually dimorphic effects of E2 on SC-LTP originates from its interactions with the $\mathrm{ER} \alpha$ receptor in females, and they suggest that the downstream effects are likely to occur at the synapse rather than in the nucleus.

Next, Wang et al. (2018) investigated the relevant molecular signaling mechanisms involved in this ER $\alpha$-mediated effect. An involvement of the kinases Src and Erk1/2 is likely, given their role in the immediate component of NMDARassociated signaling and their link to $\mathrm{ER} \alpha$ in neurons (Woolley, 2007). Wang et al. (2018) did, in fact, find that the increased colocalization of phosphorylated Erk1/2 and Src with PSD-95 that normally occurs after TBS was abolished in the presence of a selective $\operatorname{ER} \alpha$ antagonist in females, but not in males. Furthermore, changes in the actin cytoskeleton that normally occur downstream of Src and Erk1/2 activation and are required for LTP stabilization were comparable between the sexes. Together, these results suggest that ERK1/2 
and Src signaling are the critical targets of $\mathrm{ER} \alpha$ action in the context of LTP.

Wang et al. (2018) also found that $\operatorname{ER} \alpha$ is expressed at higher levels in female than in male CA1, regardless of estrus stage. More specifically, both the density of postsynaptic $\operatorname{ER} \alpha$ and the relative percentage of $\mathrm{ER} \alpha$-positive synapses were greater in females, whereas expression levels of ER $\beta$ and GPER1 were similar in males and females. This observation is crucial as it provides a primary neurobiological basis for the ER $\alpha$ dependency of female SC-LTP and its associated downstream signaling. As a consequence of the lower ER $\alpha$ levels, the effects of E2 on SCLTP are likely to be smaller in males than in females. This might explain why ER $\alpha$ antagonism affects SC-LTP differentially in the two sexes.

After finding that activation of $\mathrm{ER} \alpha$ increases phosphorylation of ERK and Src even in the absence of TBS, Wang et al. (2018) predicted that the effects of E2 on the phosphorylation of these kinases would be additive with regard to LTP. In females, phosphorylation of these kinases is $\mathrm{ER} \alpha$ dependent, suggesting that TBSdependent mechanisms for their activation are weaker in females than in males. If so, the threshold for SC potentiation in females should be higher in the absence of E2 than in its presence. Electrophysiological recordings showed that stimulation with five theta-burst pairs at 2 min intervals was sufficient to elicit SC-LTP in male, but not female, slices. In contrast, the application of four theta-burst triplets resulted in robust LTP in females. When E2 was infused during two-burst stimulation in female slices, LTP levels resembled those seen in male slices. This effect was mediated by both $\mathrm{ER} \alpha$ and $\mathrm{ER} \beta$, as revealed by the application of the respective receptor antagonists. Therefore, these results support the hypothesis that E2 lowers the threshold for LTP induction threshold in females.

The ability of E2 to lower the threshold for inducing SC-LTP in female mice suggests that memory might be influenced by circulating E2 levels. Wang et al. (2018) tested this hypothesis with an objectlocation memory task in proestrus and nonestrus female mice, in which circulating levels of E2 are higher and lower, respectively. During a 5 min encoding period, animals explored two objects in an arena. Hippocampus-dependent memory was assessed $24 \mathrm{~h}$ later, after the spatial location of one object had been changed. Female mice in proestrus spent significantly more time exploring the object in the novel location than their nonestrus counterparts did, suggesting better encoding and recall of memory when the circulating E2 level was higher. This effect was abolished by peripheral application of $\mathrm{ER} \alpha$ - or $\mathrm{ER} \beta$-selective antagonists in proestrus animals, consistent with the earlier in vitro results.

Arguably, the most perplexing result of the Wang et al. (2018) study is that TBSinduced depolarizing potentials, in the absence of ER $\alpha$ function, are insufficient to activate Erk1/2 and Src signaling and to induce stable SC-LTP in females despite being adequate in males. Wang et al. (2018) propose that this stems from sexually dimorphic cation influx-independent interactions between NMDARs and submembrane proteins. For example, metabotropic signaling of NMDARs regulates Src activity during excitotoxicity (Weilinger et al. 2016), and $\mathrm{Ca}^{2+}$ independent coactivation of NMDARs and mGLuR5 has been shown to increase the phosphorylation of ERK (Yang et al. 2004). Why such mechanisms differ between males and females remains unclear. Variations in subunit composition of NMDARs between males and females provide a simple explanation, but this seems unlikely because initial NMDAR activity was comparable between the sexes. Divergence in function could instead occur by virtue of NMDAR modulation. Other work has, in fact, demonstrated that E2-dependent signaling via G-proteincoupled receptor-30 can regulate NMDAR function in the rodent hippocampus (Liu et al., 2012). The receptor partly exerts this effects by coupling to the Erk1/2 signaling cascade and phosphorylating NMDARs, which might alter the downstream coupling of the receptor to other effectors (Dore et al., 2017).

A second explanation for the difference in the E2 dependence of LTP in males and females might be structural and functional differences in cholinergic signaling between the sexes. The cholinergic system directly modulates NMDAR function (Flores-Hernandez et al., 2009), and the expression of sex hormone receptors within cholinergic neurons is known to differ between sexes. In rodents, subsets of male cholinergic neurons express androgen receptors whereas female cholinergic neurons express ER $\alpha$ (Giacobini and Pepeu, 2018). Moreover, the effects of E2 on NMDARs have been shown to be mediated via the cholinergic system in females but not males (Volosin et al., 2006; Hyer et al., 2018). Overall, these findings point toward a cooperative role of E2 signaling and the cholinergic system in the modulation of NMDAR function.
Can alternative mechanisms account for the sexual dimorphism of hippocampal LTP? Another study (Qi et al., 2016) focused on a different hippocampal circuit, the temporoammonic (TA)-CA1 pathway. In brief, they found that male rats express more GluA1-containing AMPARs and GluN1containing NMDARs on the postsynaptic membrane of TA-CA1 synapses than female rats. Furthermore, male rats displayed larger TA-CA1 LTP and better long-term $(>7 \mathrm{~d})$ retention of spatial memory in the Morris water maze. This suggests that differing molecular pathways can underpin the sexual dimorphism of LTP in different circuits. Therefore, cognitive differences between males and females likely result from the complex interplay of multiple sexually dimorphic pathways.

\section{References}

Andreano JM, Cahill L (2009) Sex influences on the neurobiology of learning and memory. Learn Mem 16:248-266.

Bender RA, Zhou L, Vierk R, Brandt N, Keller A, Gee CE, Schäfer MK, Rune GM (2017) Sexdependent regulation of aromatase-mediated synaptic plasticity in the basolateral amygdala. J Neurosci 37:1532-1545.

Dore K, Stein IS, Brock JA, Castillo PE, Zito K, Sjöström PJ (2017) Unconventional NMDA receptor signaling. J Neurosci 37:1080010807.

Flores-Hernandez J, Salgado H, De La Rosa V, Avila-Ruiz T, Torres-Ramirez O, LopezLopez G, Atzori M (2009) Cholinergic direct inhibition ofN-methyl-D aspartate receptormediated currents in the rat neocortex. Synapse 63:308-318.

Giacobini E, Pepeu G (2018) Sex and gender differences in the brain cholinergic system and in the response to therapy of Alzheimer disease with cholinesterase inhibitors. Curr Alzheimer Res 15:1077-1084.

Hyer MM, Phillips LL, Neigh GN (2018) Sex differences in synaptic plasticity: hormones and beyond. Front Mol Neurosci 11:266.

Kramár EA, Chen LY, Brandon NJ, Rex CS, Liu F, Gall CM, Lynch G (2009) Cytoskeletal changes underlie Estrogen's acute effects on synaptic transmission and plasticity. J Neurosci 29: 12982-12993.

Liu SB, Zhang N, Guo YY, Zhao R, Shi TY, Feng SF, Wang SQ, Yang Q, Li XQ, Wu YM, Ma L, Hou Y, Xiong LZ, Zhang W, Zhao MG (2012) G-protein-coupled receptor 30 mediates rapid neuroprotective effects of estrogen via depression of NR2B-containing NMDA receptors. J Neurosci 32:4887-4900.

Ooishi Y, Kawato S, Hojo Y, Hatanaka Y, Higo S, Murakami G, Komatsuzaki Y, Ogiue-Ikeda M, Kimoto T, Mukai H (2012) Modulation of synaptic plasticity in the hippocampus by hippocampus-derived estrogen and androgen. The Journal of Steroid Biochemistry and Molecular Biology 131:37-51.

Pedram A, Razandi M, O’Mahony F, Harvey H, Harvey BJ, Levin ER (2013) Estrogen re- 
duces lipid content in the liver exclusively from membrane receptor signaling. Sci Signal 6:ra36.

Pedram A, Razandi M, Lewis M, Hammes S, Levin ER (2014) Membrane-localized estrogen receptor $\alpha$ is required for normal organ development and function. Dev Cell 29:482-490.

Qi X, Zhang K, Xu T, Yamaki VN, Wei Z, Huang M, Rose GM, Cai X (2016) Sex differences in long-term potentiation at temporoammonicCA1 synapses: potential implications for memory consolidation. PLoS One 11:e0165891.

Vierk R, Glassmeier G, Zhou L, Brandt N, Fester L, Dudzinski D, Wilkars W, Bender RA, Lewerenz M, Gloger S, Graser L, Schwarz J, Rune
GM (2012) Aromatase inhibition abolishes LTP generation in female but not in male mice. J Neurosci 32:8116-8126.

Volosin M, Song W, Almeida RD, Kaplan DR, Hempstead BL, Friedman WJ (2006) Interaction of survival and death signaling in basal forebrain neurons: roles of neurotrophins and proneurotrophins. J Neurosci 26:7756-7766.

Wang W, Le AA, Hou B, Lauterborn JC, Cox CD, Levin ER, Lynch G, Gall CM (2018) Memoryrelated synaptic plasticity is sexually dimorphic in rodent hippocampus. J Neurosci 38:79357951.

Weilinger N, Lohman AW, Rakai BD, Ma EM, Bialecki J, Maslieieva V, Rilea T, Bandet MV,
Ikuta NT, Scott L, Colicos MA, Teskey GC, Winship IR, Thompson RJ (2016) Metabotropic NMDA receptor signaling couples src family kinases to pannexin-1 during excitotoxicity. Nat Neurosci 19:432-442.

Woolley CS (2007) Acute effects of estrogen on neuronal physiology. Annu Rev Pharmacol Toxicol 47:657-680.

Yang L, Mao L, Tang Q, Samdani S, Liu Z, Wang JQ (2004) A novel $\mathrm{Ca}^{2+}$-independent signaling pathway to extracellular signal-regulated protein kinase by coactivation of NMDA receptors and metabotropic glutamate receptor 5 in neurons. J Neurosci 24:10846-10857. 